\title{
Surgical Repair of Post Infarction Ventricular Septal Rupture: An 18 Years' Retrospective Multicenter Study
}

\author{
Zohre Mohammadi ${ }^{1}$, Masoud Majidi², Saman Rostambeigi ${ }^{3}$, Parham Sadeghipour ${ }^{3}$, \\ Anahita Tatavoosi ${ }^{4}$, Fateme Pourmotahari ${ }^{2}$, Pardis Ghorbani ${ }^{2}$, and Mahnoosh Foroughi ${ }^{2}$ \\ ${ }^{1}$ Tehran University of Medical Sciences \\ ${ }^{2}$ Shahid Modarres Educational Hospital \\ ${ }^{3}$ Iran University of Medical Sciences \\ ${ }^{4}$ Tehran University of Medical Sciences School of Medicine
}

January 29, 2021

\begin{abstract}
Background: Ventricular Septal Rupture (VSR) is a rare but challenging complication after myocardial infarction (MI). In the presence of acute MI, volume and pressure overload lead to acute heart decompensation. The present study was designed to evaluate the early surgical outcome of VSR for over 18 years. Method: This multicenter study was done during 2000-2018, in which 99 patients with post-MI VSR were included. Results: The patients $(n=11)$ presenting hemodynamic deterioration at the time of hospital admission, died before any attempt for surgery. A consecutive series of 88 patients with surgical repair of VSR was evaluated. The mean interval from MI to VSR diagnosis was $7.5 \pm 7.2$ days and from admission to the operation was $5 \pm 5$ days. VSR location did not influence the outcome $(\mathrm{p}=0.1)$. The concomitant coronary bypass was done for all patients; two-vessel disease was more prevalent (39\%). Only 25 patients survived and left the hospital (13 patients died in the operating room due to the failure of pump weaning and 50 patients in the ICU due to low cardiac output). Predictors of poor prognosis included low ejection fraction $(\mathrm{p}=0.01)$, prolonged pump time $(\mathrm{p}=0.01)$, and operation in the second half of this period ( $\mathrm{p}=002)$. Conclusion: Despite the improvement in perioperative management and cardiac surgery techniques, the perioperative mortality rate of VSR has remained high where the assist device is not accessible. We suggest VSR repair limited to certain centers with adequate experiences because of the low average annual number.
\end{abstract}

\section{Hosted file}

VSR manuscript.pdf available at https://authorea.com/users/392612/articles/506410surgical-repair-of-post-infarction-ventricular-septal-rupture-an-18-years-retrospectivemulticenter-study

\section{Hosted file}

Table 1.pdf available at https://authorea.com/users/392612/articles/506410-surgical-repairof-post-infarction-ventricular-septal-rupture-an-18-years-retrospective-multicenterstudy

\section{Hosted file}

Table 2.pdf available at https://authorea.com/users/392612/articles/506410-surgical-repairof-post-infarction-ventricular-septal-rupture-an-18-years-retrospective-multicenterstudy 